\title{
A new approach to the quantitative estimation of nitrogen metabolic pathways in the rumen
}

\author{
BY YOAV AHARONI* AND HAIM TAGARI \\ Department of Animal Science, Faculty of Agriculture, Rehovot 76-100, Israel \\ AND RAY C. BOSTON \\ School of Mathematics and Physical Sciences, Murdoch University, Murdoch, WA6150, Australia
}

(Received 7 February 1990-Accepted 22 January 1991)

\begin{abstract}
Rumen nitrogen metabolism values were estimated by the use of a single injection of ${ }^{15}\left(\mathrm{NH}_{4}\right)_{2} \mathrm{SO}_{4}$ into the rumen of sheep and consecutive ${ }^{15} \mathrm{~N}$ enrichment measurements in the rumen ammonia pool, rumen non- $\mathrm{NH}_{3}-\mathrm{N}$ (NAN) pool, rumen purine pool and blood urea-N (BUN) pool for a period of $24 \mathrm{~h}$. Synthesis and degradation of $\mathbf{N}$ compounds in the rumen and passage of $\mathrm{N}$ to and from the rumen were evaluated on a chemical rather than a microbial basis; microbial fractions were not separated. This model was examined in two experiments. In Expt 1 a ram $(55 \mathrm{~kg})$ was given a semi-synthetic diet $(1067 \mathrm{~g} \mathrm{dry}$ matter (DM), $22.8 \mathrm{~g} \mathrm{~N}$ ) in which soya-bean meal provided over $90 \%$ of the $\mathrm{N}$. In Expt 2, two rams (45 kg) were given in three consecutive periods a semi-synthetic basal diet containing: (1) roasted soya-bean meal (SBM, $725 \mathrm{~g} \mathrm{DM,} 14.8 \mathrm{~g} \mathrm{~N} / \mathrm{d}$ ); or (2) fishmeal (FM, $728 \mathrm{~g} \mathrm{DM,} 15.5 \mathrm{~g} \mathrm{~N} / \mathrm{d}$ ); or (3) raw soya-bean meal (RSBM, $724 \mathrm{~g} \mathrm{DM,} 13.8 \mathrm{~g} \mathrm{~N} / \mathrm{d}$ ). In all these rations, the main protein source provided over $90 \%$ of the $\mathrm{N}$. In Expt 1, 68.3\% of $\mathrm{N}$ intake was degraded directly to $\mathrm{NH}_{3}$ in the rumen, $21 \cdot 2 \%$ escaped rumen degradation and $10.5 \%$ was incorporated into stable $\mathrm{N}$ compounds in the rumen. $\mathrm{Net}^{\mathrm{NH}}$ transfer to the blood was $30.4 \%, \mathrm{NH}_{3}$ flow from the rumen was $6.6 \%$ and rumen $\mathrm{NAN}$ output was $63 \%$ of $\mathrm{N}$ intake. In Expt 2, rumen NAN output was larger $(7.67,14.36$ and $8.89 \mathrm{~g} \mathrm{~N} / \mathrm{d}$ for diets containing SBM, FM and RSBM respectively; $P<0.05)$ and net $\mathrm{NH}_{3}$ loss to the blood was smaller $(6 \cdot 1,0 \cdot 39$ and $4 \cdot 17 \mathrm{~g} \mathrm{~N} / \mathrm{d}$ for diets SBM, FM and RSBM respectively; $P<0.05$ ) for diet FM as compared with the soya-bean diets. The percentage of rumen NAN that was synthesized from $\mathrm{NH}_{3}$ was larger for diet RSBM (36.4, 40.3 and $49 \cdot 1$ for diets SBM, FM and RSBM respectively; $P<0.05$ ) than for the other two rations. $\mathrm{NH}_{3}$ pool sizes $(\mathrm{g} \mathrm{N})$ were $0.463,0.385$ and 0.301 for diets SBM, FM and RSBM respectively $(P<0.05)$, while their hourly turnover rates were $15.8,26 \cdot 1$ and 5.12 for diets SBM, FM and RSBM respectively $(P<0.01)$, indicating no correlation between pool size and its turnover rate. The existence of a small and rapidly turning over NAN pool to which $\mathrm{NH}_{3}$ is first bound (SNAN1) was indicated by the difference in the shape of the NAN and purines ${ }^{15} \mathrm{~N}$-enrichment curves in the first $3 \mathrm{~h}$ after label injection. The fact that the rate of $\mathrm{NH}_{3}$ initial binding to SNAN1 pool was related neither to ammonia pool size nor to SNAN1 pool size suggests the existence of an unknown control mechanism at this site.
\end{abstract}

Nitrogen: Metabolic pathways: Rumen

Nitrogen-containing feedstuffs entering the rumen are partly degraded to ammonia, free amino acids and other simple $\mathrm{N}$ compounds. Rumen micro-organisms, bacteria and protozoa, use these $\mathrm{N}$ compounds to synthesize their body protein. The non- $\mathrm{NH}_{3}-\mathrm{N}$ (NAN) that flows from the forestomachs (rumen and reticulum) is composed of undegraded feed NAN and NAN of microbial origin. The amount of NAN leaving the forestomachs is affected by the amount of NAN given, the extent of feed NAN degradation, and microbial NAN synthesis and degradation in the rumen. As $\mathrm{NH}_{3}$ is absorbed through the

\footnotetext{
*Present address: Agricultural Research Organization Experimental Station, Neve-Ya'ar, PO Haifa 31999. Israel.
} 
rumen wall, and blood urea and endogenous protein enter the rumen, rumen $\mathrm{N}$ output may be lower or higher than $\mathrm{N}$ intake, depending on the net $\mathrm{N}$ loss or gain by these pathways.

Methods for estimating the outcome of rumen $\mathrm{N}$ metabolism commonly attempt to define the contributions of undegraded feed $\mathrm{N}$ (or protein) and microbial $\mathrm{N}$ to the NAN flowing out of the forestomachs or entering the duodenum. Microbial protein in duodenal digesta is identified by the use of a microbial marker. The concentration of such a marker, either natural or isotopic, is determined in clean and representative microbial samples and in the total digesta. The ratio of these two concentrations, relative to the NAN concentrations in the samples, is used to calculate the ratio microbial $\mathrm{N}$ : total NAN in the digesta. In some cases, endogenous or fungal NAN contributions are also estimated. All the rest of NAN in the sample, according to this definition, is considered to be undegraded feed NAN. The amount of undegraded feed $N$ entering the duodenum is then calculated as the product of NAN flow, measured using indigestible liquid and particulate markers, and the calculated proportion.

The microbial population of the rumen is not homogeneous and the ratio $\mathrm{N}$ : marker in different fractions of this population may differ substantially. Estimations of the ratio microbial $\mathrm{N}$ :total NAN in the digesta entering the proximal duodenum reported by different workers using different marker techniques were summarized by Smith (1975); there were large variations in this ratio between markers with similar diets and between workers using the same marker.

A new approach is suggested here for the definition and quantitative estimation of rumen $\mathrm{N}$ metabolism. Instead of the partition of rumen NAN between microbial and feed NAN, a partition of NAN synthesized from $\mathrm{NH}_{3}$ in the rumen, synthetic NAN (SNAN) $v$. feedoriginated NAN (FNAN) is suggested. ${ }^{15}\left(\mathrm{NH}_{4}\right)_{2} \mathrm{SO}_{4}$ was used to label the $\mathrm{NH}_{3}$ pool in the rumen. On the basis of this definition, all the determination of ${ }^{15} \mathrm{~N}$ enrichments in rumen fractions were carried out on samples of total rumen contents, which were separated by chemical rather than biological criteria into three fractions: (1) rumen ammonia, (2) rumen NAN, (3) rumen purines. Rumen microbial fractions were neither separated nor defined. It was assumed that every rumen NAN fraction, defined either on a chemical or a biological basis, was composed of both SNAN and FNAN. In addition to rumen content samples, blood samples were taken for determination of ${ }^{15} \mathrm{~N}$ enrichments in blood urea-N (BUN).

The aim of the present study was to examine the ability of the new definition to indicate consistent differences between different protein sources. In one experiment, rumen $\mathrm{N}$ metabolism variables were estimated in one ram given one diet, without replicates. In a second experiment, two rams were given three protein sources, supplied in sequence at maintenance level. In both experiments, the variables were estimated by compartmental analysis techniques, using the CONSAM computer program (Boston et al. 1982).

\section{MATERIALS AND METHODS}

\section{Experimental design}

Expt 1: One $55 \mathrm{~kg}$ Awassi ram fitted with a large rumen fistula (diameter $90 \mathrm{~mm}$ ) and a T-shaped cannula in the proximal duodenum about $50 \mathrm{~mm}$ beyond the pylorus was maintained indoors in a metabolism cage. A semi-synthetic diet containing commercial roasted soya-bean meal as the main protein source was offered in six and twelve daily meals for the first 2 weeks of adaptation respectively, then in twenty-four daily meals for the last $2 \mathrm{~d}$ preceding the sample collection period and for the $2 \mathrm{~d}$ of sampling. Diet composition and daily intakes of dry matter (DM), $\mathrm{N}$ and chromium that was mixed in the diet in the form of $\mathrm{Cr}$-mordanted acid-detergent fibre (ADF) are given in Table 1 . In the first $24 \mathrm{~h}$ sampling, samples of whole rumen contents, duodenal digesta and faeces were taken at six- 
cylinder was inserted via the rumen fistula, opened once in place and closed after at least one cycle of reticular contraction and expansion to remove any elongated particles which may have been pushed into the reticulum with the cylinder. This sampling procedure was tested in our laboratory for estimations of $\mathrm{DM}$ and $\mathrm{N}$ flow from the rumen (see pp. 411-412), and it was concluded that those samples could represent the DM and $\mathrm{N}$ flow to the omasum. Duodenal digesta were collected from the duodenal cannula by free flow into a test-tube. Rumen samples (about $50 \mathrm{ml}$ ) were transferred to wide flasks and stored immediately at $-18^{\circ}$. Faeces were taken from the rectum by grab sampling, about $50 \mathrm{~g}$ each time. Zero rumen, duodenal $(25 \mathrm{ml}$ each time) and faecal samples were collected in plastic flasks that were kept at $-18^{\circ}$ an to which the samples were added at each sampling time. Jugular blood samples were taken by $5 \mathrm{ml}$ heparinized syringes, put on ice and analysed on the same day.

Rumen samples were prepared for analysis by the following procedure: to a weighed frozen sample of about $45 \mathrm{~g}$ in a $250 \mathrm{ml}$ wide plastic flask, $100 \mathrm{ml}$ distilled water were added and the sample was homogenized on ice. During homogenization, portions were taken for NAN determination and for the separation of a supernatant fraction for the determination of $\mathrm{NH}_{3}$ and soluble $\mathrm{Cr}$; the rest of the sample was taken for DM determination and then ground for purine- $\mathrm{N}$ determination. Ash and mordanted $\mathrm{Cr}$ were determined in zero-time dried rumen samples as well as in duodenal and faecal samples and in feeds. Duodenal digesta were treated in the same way except that less water was added to the samples. Faeces were ground wet and samples were taken for $\mathrm{N}$ determination. The rest of the sample was dried for further analyses. Lignin was determined in zero-time rumen and duodenal digesta samples and in faeces and feeds in Expt 2.

\section{Analytical procedures}

$N A N$ determination and collection. A $2 \mathrm{ml}$ homogenized rumen sample was placed in a $75 \mathrm{ml} \mathrm{Kjeldahl} \mathrm{test} \mathrm{tube,} 0.2 \mathrm{ml}$ of saturated potassium carbonate solution were added to the sample and the test tube was heated in water-bath to $80^{\circ}$ for 40 min for $\mathrm{NH}_{3}$ removal. In a preliminary study, this procedure was tested by the addition of different quantities of unlabelled ammonium salt to samples containing ${ }^{15} \mathrm{~N}$ in both $\mathrm{NH}_{3}$ and $\mathrm{NAN}$ fractions. The amounts and ${ }^{15} \mathrm{~N}$-enrichment levels of NAN were not affected by the unlabelled $\mathrm{NH}_{3}$ additions when $\mathrm{NH}_{3}$ was added at up to twenty times the original concentration. The sample was digested by a Kjeldahl procedure with $5 \mathrm{ml}$ digestion solution (Aharoni \& Tagari, 1990) and, after cooling, was made up to $10 \mathrm{ml}$. Portions of $1 \mathrm{ml}$ were transferred to microdiffusion Conway dishes (Conway, 1957) with $1 \mathrm{ml} 10 \mathrm{M}$-sodium hydroxide as the alkaline agent. $\mathrm{NH}_{3}$ was collected in $1 \mathrm{ml} 0.025 \mathrm{M}$ - or $0.3 \mathrm{ml} 0.05 \mathrm{M}$-sulphuric acid for $\mathrm{N}$ determination or ${ }^{15} \mathrm{~N}$ assay, respectively. $\mathrm{N}$ was determined by the phenol method (Chaney \& Marbach, 1962).

Separation of a supernatant fraction in rumen samples. A $25 \mathrm{ml}$ portion of homogenized rumen content was added to $5 \mathrm{ml}$ trichloroacetic acid $(250 \mathrm{~g} / \mathrm{l})$ in a $50 \mathrm{ml}$ weighed tube, vortexed and centrifuged at $14000 \mathrm{~g}$ for $30 \mathrm{~min}$. The supernatant fraction was collected and used for ammonia and soluble $\mathrm{Cr}$ determinations.

$\mathrm{NH}_{3}$ determination and collection. $\mathrm{NH}_{3}$ in the supernatant fraction was determined by the microdiffusion technique described previously. Portions of 1 or $2 \mathrm{ml}$ were taken and collected in $1 \mathrm{ml} 0.025 \mathrm{M}-\mathrm{H}_{2} \mathrm{SO}_{4}$ or $0.2 \mathrm{ml} 0.05 \mathrm{M}-\mathrm{H}_{2} \mathrm{SO}_{4}$ for $\mathrm{N}$ determination or ${ }^{15} \mathrm{~N}$ assay respectively. Saturated $\mathrm{K}_{2} \mathrm{CO}_{3}$ solution ( 1 or $2 \mathrm{ml}$ ) replaced the $\mathrm{NaOH}$ for $\mathrm{N}$ determination or ${ }^{15} \mathrm{~N}$ assay respectively.

Soluble $\mathrm{Cr}$ determination. A portion of the supernatant fraction was diluted to give $\mathrm{Cr}$ concentrations of $2-5 \mathrm{mg} / 1$ and $\mathrm{Cr}$ was determined by the atomic absorption procedure. The supernatant fractions of zero-time samples of rumen contents were used for each ram 
as blanks. Standards were prepared as solutions of sodium dichromate in water. Values of blanks, as compared with distilled water, were found to be very close to zero, indicating that no mordanted $\mathrm{Cr}$ was found in the rumen solution.

Mordanted $\mathrm{Cr}$ determinations. Dried and ground zero-time samples of rumen contents, duodenal digesta, faeces and diets were weighed on $\mathrm{Cr}$-free paper in amounts that were calculated to give about $100 \mu \mathrm{g} \mathrm{Cr} /$ sample $(0 \cdot 25-1 \cdot 0 \mathrm{~g} \mathrm{DM})$. The sample, wrapped in the weighing paper, was digested in a micro-Kjeldahl tube in a mixture of $5.0 \mathrm{ml} 10.8 \mathrm{M}$-nitric acid $+1.5 \mathrm{ml} 9.9 \mathrm{M}$-hydrochloric acid in a heating block. $\mathrm{HNO}_{3}(5.0 \mathrm{ml})$ was added after at least half the volume had evaporated and the heating was continued until about $3 \mathrm{ml}$ of solution were left. After cooling, the sample was diluted with distilled water and was quantitatively transferred through a filter paper (Whatman ashless no. 41 ) to a $50 \mathrm{ml}$ volumetric flask and was brought to volume. The $\mathrm{Cr}$ concentration was determined directly in the filtrate by atomic absorption, using the same standards as for soluble $\mathrm{Cr}$ determinations. Blanks of unlabelled feeds, faeces and rumen contents gave zero values by this procedure, so the routine use of a blank was omitted.

Purine determination and collection. Purine- $\mathrm{N}$ and ${ }^{15} \mathrm{~N}$ enrichment were determined by a modification (Aharoni \& Tagari, 1990) of the procedure of Zinn \& Owens (1982).

$B U N$ determination and collection. Three portions of $1 \mathrm{ml}$ whole blood were taken of each blood sample for $(a)$ free $\mathrm{NH}_{3}-\mathrm{N}$ determination, (b) (urea + free $\mathrm{NH}_{3}-\mathrm{N}$ ) determination and (c) (urea + free $\mathrm{NH}_{3}{ }^{-15} \mathrm{~N}$ ) determination. The portions were placed in Conway dishes containing either $0.1 \mathrm{ml} 0.1 \mathrm{M}$-phosphate buffer, $\mathrm{pH} 7.0$ for portion $a$ or $0.1 \mathrm{ml}$ urease (EC 3.5.1.5; Sigma U-4002, $300 \mu$ molar units $/ 0.1 \mathrm{ml}$ ) dissolved in buffer solution for portions $b$ and $c$ and allowed to stand for $20 \mathrm{~min}$ at room temperature. Saturated $\mathrm{K}_{2} \mathrm{CO}_{3}$ $(1 \mathrm{ml})$ was added to each of the dishes for a diffusion period of $90 \mathrm{~min}$ and the $\mathrm{NH}_{3}$ was collected in the central chamber of the dish in either $1.0 \mathrm{ml} 0.05 \mathrm{M}-\mathrm{H}_{2} \mathrm{SO}_{4}$ for portions $a$ and $b$ or in $0.4 \mathrm{ml} 0 \cdot 1 \mathrm{M}-\mathrm{H}_{2} \mathrm{SO}_{4}$ for portion $c$. $\mathrm{N}$ was determined by the phenol method (Chaney \& Marbach, 1962).

Other determinations. DM was determined by drying all samples except feeds at $60^{\circ}$ for $48 \mathrm{~h}$. Feeds were dried at $105^{\circ}$ for $24 \mathrm{~h}$. Kjeldahl $\mathrm{N}$ was determined on wet materials for all samples except feeds, in which it was determined on dried and ground samples. Ash was determined by igniting at $600^{\circ}$ for $3 \mathrm{~h}$. Acid-detergent lignin was determined by the procedure of Goering \& Van Soest (1975).

Samples were prepared for ${ }^{15} \mathrm{~N}$ determinations by the procedure of Feigenbaum \& Hadas (1974) and determined by light emission spectrometry in a Statron NOI-5 ${ }^{15} \mathrm{~N}$ analyser (VEB Statron, Furstenwalde, Germany).

\section{CALCULATIONS}

Rumen liquid volume and turnover rate were calculated using the linear regression of the natural logarithm of soluble $\mathrm{Cr}$ concentration $v$. time. Rumen $\mathrm{NH}_{3}$, pool size and rate of flow were then calculated on the basis of $\mathrm{NH}_{3}$ concentration in the rumen liquid phase.

Calculation of DM digestion from rumen samples was based on the assumption that the digesta collected was representative of digesta passing to the omasum. This assumption was tested by comparing these estimates of DM digestion with those based on duodenal samples. In studies of our laboratory (Y. Aharoni and H. Tagari, unpublished results) DM digested in the rumen was estimated in three rams by $\mathrm{Cr}$ concentrations in reticular samples that were taken by the procedure described previously and by duodenal $\mathrm{Cr}$ concentrations. Average digestibility estimations were 0.540 and 0.531 for reticular and duodenal estimations respectively, with the largest difference being 0.046 .

In Expt 2, the $\mathrm{Cr}$-mordanted ADF was ground before the ration was mixed and rumen $\mathrm{Cr}$ concentrations were unacceptably low while duodenal concentrations were unacceptably 
high. DM digestibility in the rumen was 0.269 (SE 0.062) and 0.625 (SE 0.093) as calculated for rumen and duodenal $\mathrm{Cr}$ concentrations respectively for the six replicates of this experiment. An attempt was made to assess rumen digestibility estimations from lignin content, but concentrations were higher in rumen than in duodenum. DM digestibility in the rumen was 0.601 (SE 0.102) and 0-322 (SE 0.212) as calculated for rumen and duodenal lignin concentrations respectively. Correlations between these four sets of data were poor, so rumen digestibility estimations and NAN flow rates from the rumen were not available for Expt 2. Apparent digestibilities of DM and $\mathrm{N}$ were calculated on the basis of $\mathrm{Cr}$ and $\mathrm{N}$ concentrations of the faeces $\mathrm{DM}$ in relation to diet $\mathrm{DM}$ content of $\mathrm{Cr}$ and $\mathrm{N}$.

Calculations of urea body pool size in goats (Brosh, 1985) suggest that blood urea concentrations represent a body liquid pool which occupies $42 \%$ of the body live weight. Similar calculations in milking cows (Bruckental et al. 1980) suggest a value of $51 \%$ of body live weight. In this study, the first estimate was used as input to the model of urea body pool size.

\section{Modelling of rumen kinetics}

CONSAM (Berman et al. 1962; Boston et al. 1982), a digital computer program developed for the analysis of data in terms of models, was used to construct the model and to fit its parameters to the observed data. In this program any set of mathematical equations (differential, integral or algebraic) or functions may serve as a model provided an analytical or numerical procedure exists for its solution. A library of model types is incorporated within the program for routine use. In the case of compartmental analysis, a set of ordinary linear and non-linear differential equations simulates a system comprising several pools (compartments) of the detected substance, which are connected by flows of that substance between them. Each flow, either between pools or from a pool to the outside, is characterized by its fractional rate, i.e. the part of the donor pool that flows on this route per unit time.

A label injected into one pool will be delivered to the other pools in relation to these fractional flow rates. A steady-state situation, for example when the masses of pools and the flow rates are constant within the experimental period, may be established by inserting an input rate of unlabelled substance into at least one of the pools. Under these conditions, the program calculates the predicted amounts of the label in the different pools for any given time after the label injection, assuming homogeneous distribution of the label within the pools. In this way, the amount of label leaving a certain pool in a certain unit time equals the sum of fractional flows out of that pool multiplied by the amount of label in that pool at that time. The same amount of label is subtracted from the total amount of the donor pool and added to the total amount of the receiving pool. The new amounts of label in the different pools serve as a base for the calculations of the next unit time. Concentrations of the label in the various pools for any given time are calculated as the label amounts in those pools at that time, divided by the pool masses, which are constant in steady-state conditions.

The program uses, in addition to the set of equations that define the model, a set of all the observed data, time-independent (e.g. measured rates of flow and pool masses) and all the time-dependent data (e.g. label concentrations in the various pools) and a set of initial estimations of the time-independent variable (adjustable) factors (e.g. unmeasured fractional flow rates, inputs of substance to the system and pool masses). Using these initial estimates, the program produces calculated values for all the observed data-points, compares them with the observed data and changes the values of the adjustable variables to fit the calculated to the observed values.

A basic rumen model was designed to which a set of three rows of ${ }^{15} \mathrm{~N}$-enrichment data was given: $(a)$ rumen $\mathrm{NH}_{3},(b)$ rumen $\mathrm{NAN},(c)$ blood urea. It was assumed that enrichment 
levels of body protein $\mathrm{N}$ would be very low within the $24 \mathrm{~h}$ period after a single ${ }^{15} \mathrm{NH}_{3}$ dose to the rumen, so that recycling of endogenous ${ }^{15} \mathrm{~N}$ from this source would be negligible. According to these rows of data, three basic compartments were established. Pools of unlabelled N, such as the pool of undegraded NAN in the rumen, and pools that do not recycle ${ }^{15} \mathrm{~N}$ to rumen or blood urea compartments were considered to be outside the system, and all the $\mathrm{N}$ fluxes from these pools into system compartments were treated as inputs. Similarly, all the $\mathrm{N}$ fluxes from system compartments to these pools, as well as fluxes out of the body, were treated as outflows. All the possible connections between system compartments were defined in the model as fluxes.

The fit of the model by the computer program to the observed values was not satisfactory, especially in the rumen NAN compartment. The calculated enrichment values of this pool tended to rise too slowly and to decline too quickly, indicating the existence of more than one labelled compartment in this pool, which contained undegraded feed NAN (FNAN) in addition to the labelled compartment(s). Rumen ${ }^{15} \mathrm{NH}_{3}-\mathrm{N}$ is incorporated rapidly into bacterial amide compounds and then appears at a slower rate in non-amide bacterial $\mathrm{N}$ compounds (Salter et al. 1979). It was assumed that the rapid amide- $\mathrm{N}$ compartment could not be combined with the more stable fraction of the NAN to give a calculable compartment in the model and so a fourth row of data, that of rumen purine$\mathrm{N}$, was chosen to represent, in an expanded model, the more stable part of the NAN pool in the rumen (SNAN). The SNAN was divided into two compartments: SNANI for initially bound $\mathrm{N}$ and SNAN2 for the stable fraction receiving input of FNAN and a flux from SNAN1, but not of $\mathrm{NH}_{3}-\mathrm{N}$. Thus, by definition, SNAN2 is composed of both SNAN and FNAN.

For simulations of the expanded model by CONSAM, all the time-dependent data and all the available time-independent data were given. Only the $\mathrm{N}$ intake rate and the ${ }^{15} \mathrm{~N}$ dose were fixed. All the possible connections between system compartments were allowed at the beginning, and fluxes that failed to show significance were omitted or altered. Three initial criteria were defined for assessing the model: (a) a good fit, i.e. visual observation of the observed $v$. the calculated data shows a good fit of the data in all the data sets over the whole period; $(b)$ significance, i.e. the fractional standard deviations (FSD) of all the estimated variables are below $0.5 ;(c)$ consistency, i.e. the same model should fit the different animals and experiments without changes.

Of all the possible models that meet these criteria, the chosen model was the most reasonable or the least refutable on biological grounds. There is, however, a possibility of more than one version of such a model. The existence of a body urea compartment, possibly extracellular, in addition to the blood urea compartment was suggested by Bruckental et al. (1980). Addition of such a compartment, which was connected by bidirectional fluxes to the BUN compartment, improved the fit of the BUN-enrichment data. The chosen rumen model and its simulation representation are shown in Figs 1 and 2.

According to the program notation, $L(i, j)$ defines the fractional rate of flow from pool $j$ to pool $i, L(0, j)$ is the fractional rate of flow from pool $j$ to the outside, $U(i)$ is a flow from the outside into pool $i$ and $M(i)$ is the size of pool $i$. G(i) is a function defined by the user. In this model, $G(10)$ defines the combined NAN that flows out of the rumen and $G(15)$ defines the flow of bypass NAN. $R(i, j)$ defines the quantitative flow-rate from pool $j$ to pool $i$, i.e. $L(i, j)$ multiplied by $M(j)$.

\section{Statistical analysis}

FSD of the adjustable variables within animals were estimated by CONSAM, using the procedure described by Berman et al. (1962). The differences between treatments and animals in Expt 2 were tested by analysis of variance for three treatments and two blocks (animals), assuming no period effect and leaving $2 \mathrm{df}$ for the error. 


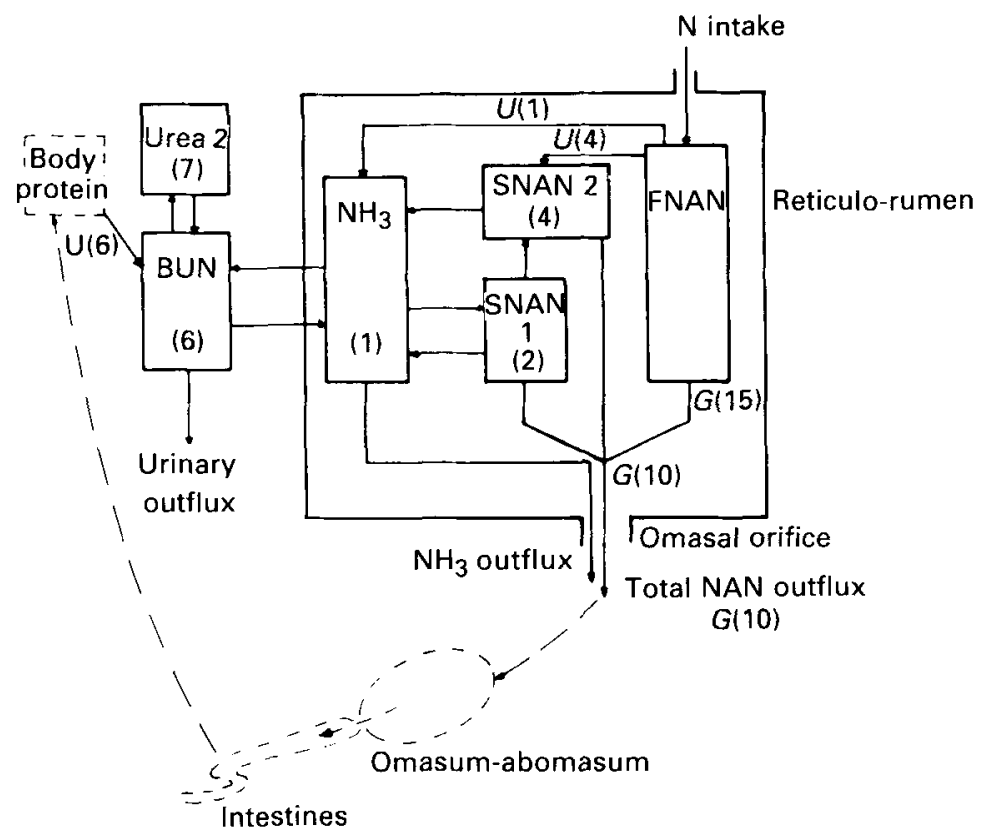

Fig. I. Rumen model. Nitrogen compartments are shown: BUN, blood urea-nitrogen; NAN, non- $\mathrm{NH}_{3}-\mathrm{N}$; SNAN1, initially bound stable N; SNAN2, stable NAN from food NAN and SNAN1. Arrows show the direction of $\mathrm{N}$ flow. Numbers in parentheses define the compartmental numbers in the CONSAM (Berman et al. 1962; Boston ef al. 1982) representation (see Fig. 2).

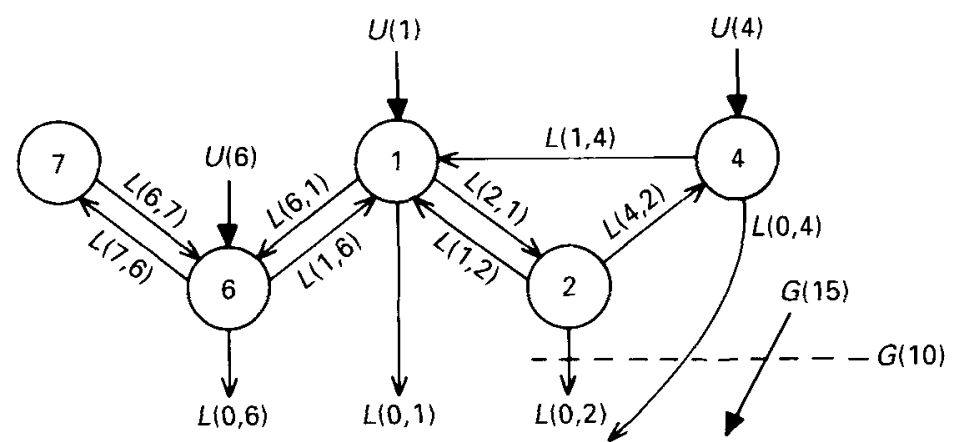

Fig. 2. CONSAM (Berman et al. 1962; Boston et al. 1982) representation of the rumen model. According to CONSAM notation, $L(i, j)$ defines the fractional rate of flow from pool $j$ to pool $i, L(0, j)$ is the fractional rate of flow from pool $j$ to the outside, $U(i)$ is a flow from the outside into pool $(i)$ and $M(i)$ is pool $i$ size. $G(i)$ is a function defined by the user. In this model, $G(10)$ defines the combined NAN that flows out of the rumen and $G(15)$ defines the flow of bypass NAN. $R(i, j)$ defines the quantitative flow-rate from pool $j$ to pool $i$, i.e. $L(i, j)$ multiplied by $M(j)$ (see Tables $3,4,5$ ).

\section{RESULTS}

Digestibilities, rumen $\mathrm{NH}_{3}-\mathrm{N}$ concentrations and pool sizes, BUN concentrations and body urea pool sizes for Expts 1 and 2 are presented in Table 2. The results for Expt 2 are means of two rams.

${ }^{15} \mathrm{~N}$-enrichment curves, fitted to the values for one ram given a semi-synthetic diet with roasted SBM as the main protein source (Expt 1) are shown in Fig. 3. Kinetic estimates 
Table 2. Expts 1 and 2. Dry matter (DM) and nitrogen digestibilities and amounts digested $(g N / d)$, rumen liquid $(l)$, rumen ammonia- $N$ and body urea- $N(g)$ pool sizes and $N$ concentrations $\left(\mathrm{mM} \mathrm{NH}_{3}\right)$ and hourly rumen liquid turnover rate of sheep receiving diets containing fishmeal $(F M)$ or soya-bean meal (SBM, RSBM)

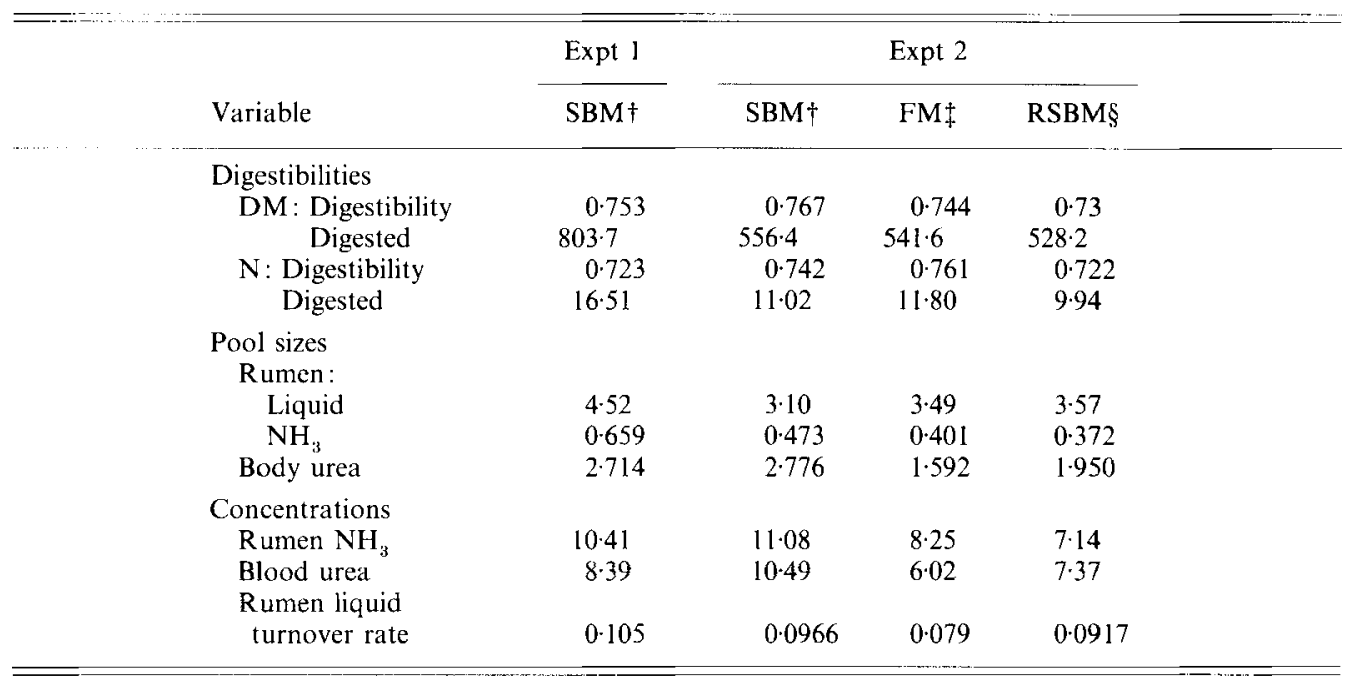

$\dagger$ Commercial roasted soya-bean meal, crude protein $(\mathrm{N} \times 6.25) 440 \mathrm{~g} / \mathrm{kg}$.

+ Herring meal, crude protein $700 \mathrm{~g} / \mathrm{kg}$.

$\$$ Raw soya-bean meal, crude protein $440 \mathrm{~g} / \mathrm{kg}$.

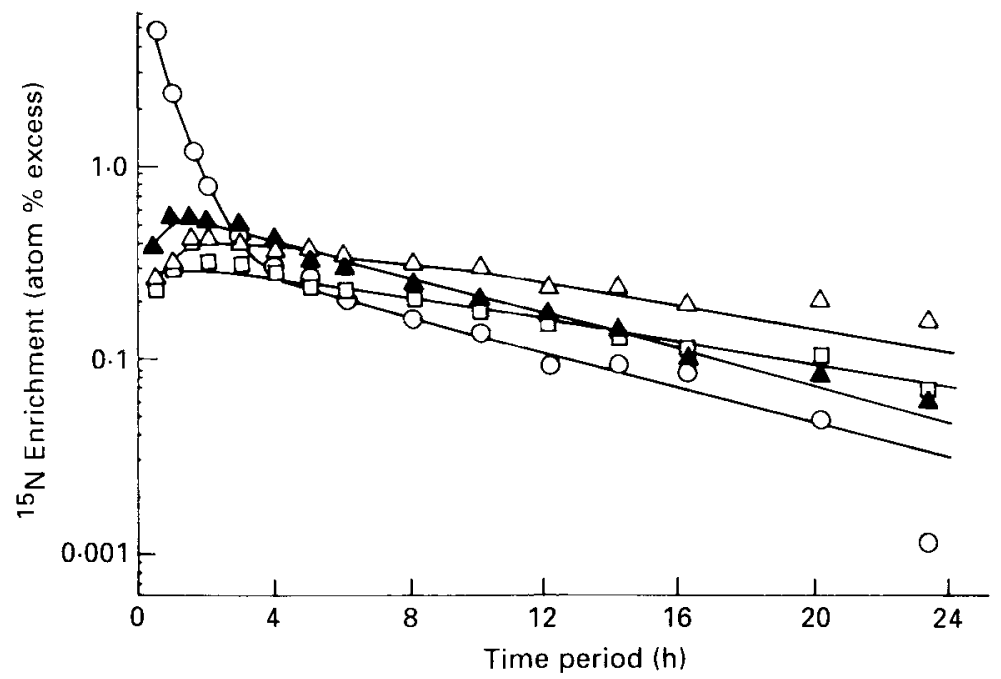

Fig. 3. Expt 1. ${ }^{15} \mathrm{~N}$-enrichment curves of one ram given a semi-synthetic diet with roasted soya-bean meal as the main protein source. Kinetic estimates were computed for these values by multi-compartmental analysis. ( $\mathrm{O}-\mathrm{O}$ ), Rumen ammonia; $(\Delta-\Delta)$, rumen purines; $\square-\square)$, rumen non- $\mathrm{NH}_{3}-\mathrm{N} ;(\boldsymbol{\Delta}-\boldsymbol{\Delta})$, blood urea-N. For details of experimental procedures and dietary treatment, see pp. 408-411 and Table 1. 
Table 3. Expt 1.* Model estimations for rumen $N$ metabolism adjustable variables and their fractional standard deviations (FSD) in one ram

(Pool sizes are given in $\mathrm{g} \mathrm{N}$ and flow rates in $\mathrm{g} \mathrm{N} / \mathrm{d}$ )

\begin{tabular}{lcc}
\hline Variable & Value & FSD \\
\hline$R(2,1) \mathrm{Ammonia}_{3}$ binding rate & $157 \cdot 89$ & $1 \cdot 319$ \\
$R(0,1) \mathrm{NH}_{3}$ outflow rate & $1 \cdot 521$ & $0 \cdot 0633$ \\
$R(6,1) \mathrm{NH}_{3}$ flow to blood & $23 \cdot 203$ & $0 \cdot 0388$ \\
$R(1,2){\mathrm{Bound} \mathrm{NH}_{3} \text { cleavage rate }}_{R}$ & $148 \cdot 23$ & $1 \cdot 381$ \\
$R(0,2)$ Bound $\mathrm{NH}_{3}$ rate of flow from the rumen & $0 \cdot 497$ & $0 \cdot 0885$ \\
$R(4,2)$ SNAN2 synthesis rate & $9 \cdot 165$ & $0 \cdot 1087$ \\
$R(1,4)$ SNAN2 degradation rate & $2 \cdot 517$ & $0 \cdot 3545$ \\
$R(1,6)$ Urea flow to rumen & $16 \cdot 265$ & $0 \cdot 1330$ \\
$R(0,6)$ Urea outflow rate & $22 \cdot 658$ & $0 \cdot 1067$ \\
$R(7,6), R(6,7)$ Urea fiow-rate to and from second urea pool & $469 \cdot 42$ & $0 \cdot 1642$ \\
$U(1)$ Feed N degraded directly to $\mathrm{NH}_{3}$ & $15 \cdot 604$ & 0.0511 \\
$U(6)$ Body N degraded to urea & $15 \cdot 720$ & $0 \cdot 0299$ \\
$P(10)$ Total NAN pool in the rumen & $8 \cdot 021$ & $0 \cdot 0339$ \\
\hline
\end{tabular}

NAN, non- $\mathrm{NH}_{3}-\mathrm{N}$; SNAN2, stable fraction of rumen NAN pool receiving input of food NAN and a flux of initially bound $\mathrm{N}$ (SNAN1) but not of $\mathrm{NH}_{3}-\mathrm{N}$.

* For details, see pp. 408-409.

$\dagger$ For definitions of flow rates, see p. 413 .

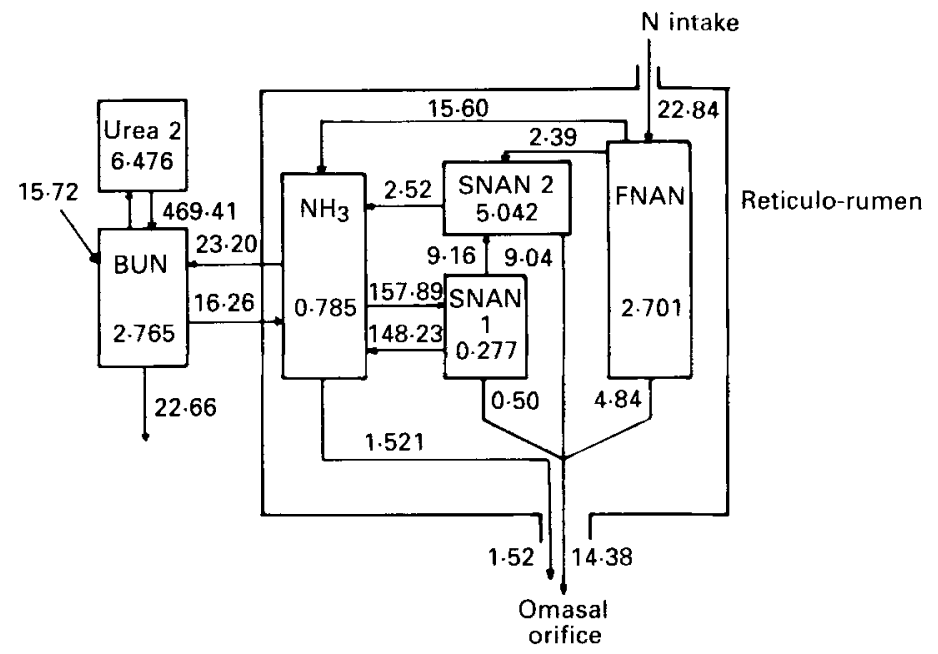

Fig. 4. Expt 1. Model estimates of nitrogen metabolism flow rates $(\mathrm{g} \mathrm{N} / \mathrm{d})$ and pool sizes ( $\mathrm{g} \mathrm{N}$ ) for one ram given a semi-synthetic diet containing soya-bean meal. For details of experimental procedures and dietary treatment, see pp. 408-411 and Table 1. BUN, blood urea-nitrogen; NAN, non- $\mathrm{NH}_{3}-\mathrm{N} ; \mathrm{SNANI}$, initially bound stable $\mathrm{N}$; SNAN2, stable NAN from food NAN and SNAN1. Arrows show the direction of N flow.

were computed from these results by multi-compartmental analysis (Berman et al. 1962). Model estimates for rumen $\mathrm{N}$ metabolism variables and their FSD are shown in Table 3.

The FSD of $R(2,1)$ and $R(1,2)$ were larger than $1 \cdot 0$, indicating that these very fast flow rates did not differ significantly from zero. This might indicate that compartment 2 is not needed for the model's solution. However, these variables were included in the model because the results of Expt 2 (described later) support their validity.

The values of the remaining flow rates and pool sizes that were included in the model derived from these fourteen adjustable variables on the assumption of steady-state 
Table 4. Expt 2.† Rumen nitrogen metabolism variables for sheep receiving diets containing fishmeal $(F M)$ or soya-bean meal (SBM, RSBM)

(Values are means of two replicates)

\begin{tabular}{|c|c|c|c|c|c|}
\hline \multirow[b]{2}{*}{ Variable } & \multicolumn{4}{|c|}{ Dietary treatment } & \multirow{2}{*}{$\begin{array}{l}\text { Statistical } \\
\text { significance of } \\
\text { treatment } \\
\text { difference }\end{array}$} \\
\hline & SBM & FM & RSBM & SEM & \\
\hline NAN rumen output $(\mathrm{g} / \mathrm{d})$ & $7 \cdot 67^{\mathrm{b}}$ & $14 \cdot 36^{\mathrm{a}}$ & $8 \cdot 89^{b}$ & 0.656 & $*$ \\
\hline Fraction of $\mathrm{N}$ intake & $0.516^{\mathrm{b}}$ & $0 \cdot 926^{a}$ & $0.646^{\circ}$ & 0.033 & $*$ \\
\hline $\begin{array}{l}\text { Net ammonia absorption: } \\
\text { proportion of intake }\end{array}$ & $0 \cdot 41 \mathrm{I}^{\mathrm{a}}$ & $0.025^{\mathrm{b}}$ & $0 \cdot 303^{\mathrm{a}}$ & 0.038 & * \\
\hline $\begin{array}{l}\mathrm{NAN} \text { synthesized from } \\
\mathrm{NH}_{3} \text { in the rumen: } \\
\text { proportion of NAN output }\end{array}$ & $0 \cdot 364^{\mathrm{b}}$ & $0 \cdot 403^{\text {at }}$ & $0.491^{\mathrm{a}}$ & $0 \cdot 015$ & $*$ \\
\hline \multicolumn{6}{|l|}{$\begin{array}{l}\text { Metabolism N flow-rates } \\
\text { as proportion of intake }\end{array}$} \\
\hline$U(1)$ & 0.229 & $0 \cdot 115$ & $0 \cdot 366$ & $0 \cdot 052$ & NS \\
\hline$U(4)$ & 0.716 & 0.814 & $0 \cdot 540$ & $0 \cdot 044$ & NS \\
\hline Bypass feed $\mathrm{N}$ & $0 \cdot 056$ & 0.071 & 0.094 & $0 \cdot 020$ & NS \\
\hline$U(6)$ & $0 \cdot 358$ & $0 \cdot 400$ & 0.420 & $0 \cdot 082$ & NS \\
\hline$R(2,1)$ & $11 \cdot 45$ & $15 \cdot 05$ & $2 \cdot 33$ & $1 \cdot 722$ & NS \\
\hline$R(0,1)$ & 0.073 & 0.049 & 0.051 & $0 \cdot 015$ & NS \\
\hline$R(6,1)$ & 0.575 & 0.493 & $0 \cdot 387$ & $0 \cdot 039$ & NS \\
\hline$R(1,2)$ & $11 \cdot 0$ & 14.45 & $1 \cdot 65$ & 1.749 & NS \\
\hline$R(0,2)$ & 0.015 & 0.017 & 0.008 & 0.006 & NS \\
\hline$R(4,2)$ & 0.439 & 0.588 & 0.676 & $0-051$ & NS \\
\hline$R(1,4)$ & 0.71 & 0.564 & 0.672 & 0.113 & NS \\
\hline$R(0,4)$ & $0.445^{\mathrm{b}}$ & $0.837^{\mathrm{a}}$ & $0.544^{b}$ & $0 \cdot 048$ & $*$ \\
\hline$R(1,6)$ & $0 \cdot 164$ & $0 \cdot 468$ & 0.047 & 0.077 & NS \\
\hline$R(0,6)$ & 0.769 & $0 \cdot 425$ & 0.723 & $0 \cdot 053$ & NS \\
\hline \multicolumn{6}{|l|}{ Turnover rates (per h) } \\
\hline $\mathrm{NH}_{3}$ pool $(i)$ & $15 \cdot 8^{\mathrm{b}}$ & $26 \cdot 1^{a}$ & $5 \cdot 1^{e}$ & 0.836 & $* *$ \\
\hline NANl pool (2) & $36 \cdot 4$ & $45 \cdot 1$ & $12 \cdot 9$ & $11 \cdot 261$ & NS \\
\hline NAN2 pool (4) & 0.095 & $0 \cdot 093$ & $0 \cdot 112$ & 0.004 & NS \\
\hline $\mathrm{NH}_{3}+\mathrm{NANI}$ pool & 1.03 & $1 \cdot 32$ & $1 \cdot 67$ & $0 \cdot 206$ & NS \\
\hline \multicolumn{6}{|l|}{ Pool sizes $(\mathrm{g} \mathrm{N})$} \\
\hline $\mathrm{NH}_{3}$ pool & $0.463^{\mathrm{a}}$ & $0.385^{b}$ & $0.301^{c}$ & 0.011 & $*$ \\
\hline SNAN1 pool & $0 \cdot 201$ & $0 \cdot 229$ & $0 \cdot 105$ & 0.054 & NS \\
\hline SNAN2 pool & $7 \cdot 95$ & $9 \cdot 99$ & $6 \cdot 5 I$ & 0.052 & NS \\
\hline
\end{tabular}

a, t. * Values with different superscript letters were significantly different: ${ }^{*} P<0 \cdot 05, * * P<0 \cdot 01$.

NS, not significant; NAN, non- $\mathrm{NH}_{3}-\mathrm{N}$; SNAN1, initially bound stable NAN; SNAN2, stable NAN from food NAN and SNAN1.

+ For details see p. 409.

$\$$ For definitions of flow rates, see p. 413 .

conditions in which pool sizes are constant and the sum of flows into each pool equals the sum of flows out of that pool. Compartment pool sizes and flow rates for one ram in Expt 1 are given in Fig. 4. 4.

Rumen $\mathrm{N}$ metabolism variables of two rams given three diets are summarized in Table

Rumen NAN output and SNAN2 flow from the rumen were higher on diet FM than on the two soya-bean meal diets $(P<0.05)$. The proportion of NAN leaving the rumen that was synthesized from $\mathrm{NH}_{3}$ was higher on diet RSBM than on the other two diets $(P<0.05)$. The rumen $\mathrm{NH}_{3}$ pool was largest on diet SBM and smallest on diet RSBM, with FM in an intermediate position $(P<0.05)$. This might be due in part to the lower level of 
Table 5. Expt 2. Rumen nitrogen metabolism variables for individual rams

(Values are means for the three diets)

\begin{tabular}{|c|c|c|c|c|}
\hline Variable & Ram 1 & Ram 2 & SEM & $\begin{array}{l}\text { Statistical } \\
\text { significance of } \\
\text { difference }\end{array}$ \\
\hline $\begin{array}{l}\text { NAN rumen output as } \\
\text { proportion of intake }\end{array}$ & 0.926 & $0 \cdot 466$ & $0 \cdot 027$ & ** \\
\hline $\begin{array}{l}\text { Net ammonia loss as } \\
\text { proportion of intake }\end{array}$ & 0.026 & 0.466 & $0 \cdot 031$ & $* *$ \\
\hline $\begin{array}{l}\text { Fraction of NAN synthesized } \\
\text { de novo in the rumen } \\
\text { Metabolism N flow rates as } \\
\text { proportion of intake }\end{array}$ & $0 \cdot 457$ & 0.381 & 0.012 & $*$ \\
\hline$U(4)$ & 0.546 & 0.833 & 0.036 & * \\
\hline$R(0,4)$ & 0.786 & 0.431 & 0.039 & $*$ \\
\hline$R(0,6)$ & 0.418 & 0.859 & 0.044 & * \\
\hline \multicolumn{5}{|l|}{ Pool sizes $(\mathrm{g} \mathrm{N})$} \\
\hline$M(1), \mathrm{NH}_{3}$ pool & $0 \cdot 288$ & 0.478 & 0.009 & $* *$ \\
\hline$M(4)$, SNAN2 pool & $6 \cdot 143$ & $10-157$ & 0.425 & * \\
\hline
\end{tabular}

$* P<0.05,{ }^{* *} P<0.01$.

NAN, non-NH $\mathrm{N}_{3} \mathrm{~N}$; SNAN2, stable fraction of rumen NAN receiving input of food NAN and a flux of initially bound $\mathrm{N}$ (SNAN1) but not of $\mathrm{NH}_{3}-\mathrm{N}$.

protein in diet RSBM. The $\mathrm{NH}_{3}$ pool turnover rate was fastest on diet FM and slowest on diet RSBM, despite the small $\mathrm{NH}_{3}$ pool on this diet $(P<0 \cdot 01)$.

The FSD of variables $R(2,1)$ and $R(1,2)$ in four of six replicates in Expt 2 were in the range $0 \cdot 12-0 \cdot 33$. The two replicates with the larger FSD (range $0 \cdot 95-1 \cdot 10$ ) were of the same treatment diet (RSBM) and the flow rates in this treatment tended to be smaller than those of the other two treatments $(P<0 \cdot 1$, Table 4$)$. The nature of these two fluxes and its influence on the estimation of SNAN1 pool size and turnover rate is discussed later.

Large and significant differences between the two rams in Expt 2 were found for several variables. These differences are summarized in Table 5.

Ram 1 was found to be superior to ram 2 in terms of rumen efficiency. Its rumen NAN output was higher and its net $\mathrm{NH}_{3}$ loss to the blood was lower than those of ram 2. Its NAN synthesis from $\mathrm{NH}_{3}$ in the rumen was higher both in absolute and in relative values, as a proportion of total NAN output. Its recycling rate of BUN to the rumen was higher and BUN excretion was lower than those of ram 2. Although the rumen $\mathrm{NH}_{3}$ pool was bigger for ram 2, it assimilated less $\mathrm{NH}_{3}$ into stable NAN compounds. SNANI turnover rate was faster for ram 2, indicating that a smaller portion of it was assimilated into stable NAN compounds and a larger portion was cleaved back to $\mathrm{NH}_{3}$. Such differences may have considerable influence on the number of replicates needed to define differences in metabolic $\mathrm{N}$ pathways due to the protein source.

\section{DISCUSSION}

Rumen NAN could be fractionated on a chemical or a biological basis to several compartments, i.e. undegraded $v$. microbial, bacterial $v$. protozoal, true protein $v$. other NAN compounds and particulate NAN $v$. liquid NAN. The question arises whether these different NAN compartments could be regarded as one common compartment, although they have different turnover and outflow rates. The simple three-compartment model, in which the rumen NAN was regarded as one common compartment, failed to fit its 
calculated ${ }^{15} \mathrm{~N}$-enrichment values to the observed data. The expanded model, which divided rumen NAN into two compartments of which one contained the purine- $\mathrm{N}$ fraction and the other did not, achieved a good fit, although this model also simplified the rumen NAN system to a great extent. It is suggested that the fast-exchange rates between rumen NAN compartments and the $\mathrm{NH}_{3}$ compartment and the good dispersal of the $\mathrm{NH}_{3}$ in the rumen equalize ${ }^{15} \mathrm{~N}$-enrichment values in NAN in different fractions in the rumen when the label is given to the $\mathrm{NH}_{3}$ pool, and thus allow a very complex system to be described in a simplified form.

The general trend of the purine- $\mathrm{N}$ was to be labelled more slowly than the NAN, and the largest differences between their ${ }^{15} \mathrm{~N}$-enrichment curves were found in the first $3 \mathrm{~h}$ after label injection. However, when the shapes of these two curves were very close to one another, compartment 2 was estimated either to be very small or to turn over very rapidly, which may put its existence into question. The validity of its existence depends on the difference between these curves, especially during the initial period after injection. Fig. $5(a, b)$ shows the differences in shape of these curves between two treatments (diet FM, Fig. 5(a); diet RSBM, Fig. $5(b)$ given to the same ram (ram 2) in Expt 2. FSD of $R(2,1)$ and $R(1,2)$ for diet FM v. diet RSBM treatments were 0.119 and $0.200 v .0 .967$ and 0.998 .

Similarly, there were three other variables with large FSD estimations - i.e. over 0.5 - in some of the replicates in Expt 2. Large FSD were found in three replicates in $R(1,6)$, in replicates in $R(7,6)$ and in two replicates in $R(6,7)$. $R(1,6)$ represents the flow of blood urea to the rumen. The existence of this flow is well documented, and the fact that in some instances it was found to be very small does not justify its exclusion from the model. $R(6,7)$ and $R(7,6)$ represent the flows in both directions between blood and body fluid urea. Direct evidence for their existence was found in experiments in which $\left[{ }^{14} \mathrm{C}\right]$ urea was injected into the blood and the decay curve in the blood of $\log { }^{14} \mathrm{C} v$. time was not linear (Bruckental et al. 1980; Tagari \& Faichney, unpublished results). Therefore, none of these variables was excluded from the model.

The flow of $\mathrm{N}$ between rumen $\mathrm{NH}_{3}$ and blood urea in Expt 1 was estimated to be much higher than reported by other workers. Flow from the rumen to blood urea and that in the opposite direction were 102 and $71 \%$ of the $N$ intake respectively, compared with a range of $444 \%$ for the first and about $10 \%$ for the latter reported for sheep (Mazanov \& Nolan, 1976; Nolan et al. 1976) and heifer calves (Bunting et al. 1989). However, these flows were lower in Expt 2 (Table 4). No correlation was evident between blood urea concentrations and amounts of urea recycled to the rumen, although the amounts recycled with diet FM tended to be higher than in the other two treatments.

The definition of degradability in this model differs from the common definition. Microbial $\mathrm{N}$, which is synthesized from both $\mathrm{NH}_{3}$ and $\mathrm{NAN}$, was not measured. In the present model, feed degraded $\mathrm{N}$ could be defined as; (1) only FNAN that was degraded directly to $\mathrm{NH}_{3}$; (2) FNAN that was degraded to $\mathrm{NH}_{3}$ plus FNAN that was incorporated into SNAN2; (3) as definition 1 but with the addition of the proportion of FNAN which was incorporated into SNAN2 and degraded later to $\mathrm{NH}_{3}$. Of these, definition 2 is probably closest to the common definition, assuming that SNAN2 is comparable to microbial N. Values of 68,79 and $71 \%$ were calculated for definitions 1,2 and 3 respectively for Expt 1 . These values agree very well with the value of $79 \%$ of SBM degraded in steers that was reported by Titgemeyer et al. (1989) and are in the range of $57-85 \%$ that was quoted by them. However, in Expt 2 the extent of degradation of all three diets, according to definition 2, was much higher (see p. 421).

Of the NAN leaving the rumen in Expt 1,53.3\% was synthesized de novo from $\mathrm{NH}_{3}$ and the rest was either undegraded feed $N$, endogenous protein- $N$ or feed $N$ that was incorporated into the synthesized pools other than via the rumen $\mathrm{NH}_{3}$ pool. The rate of 

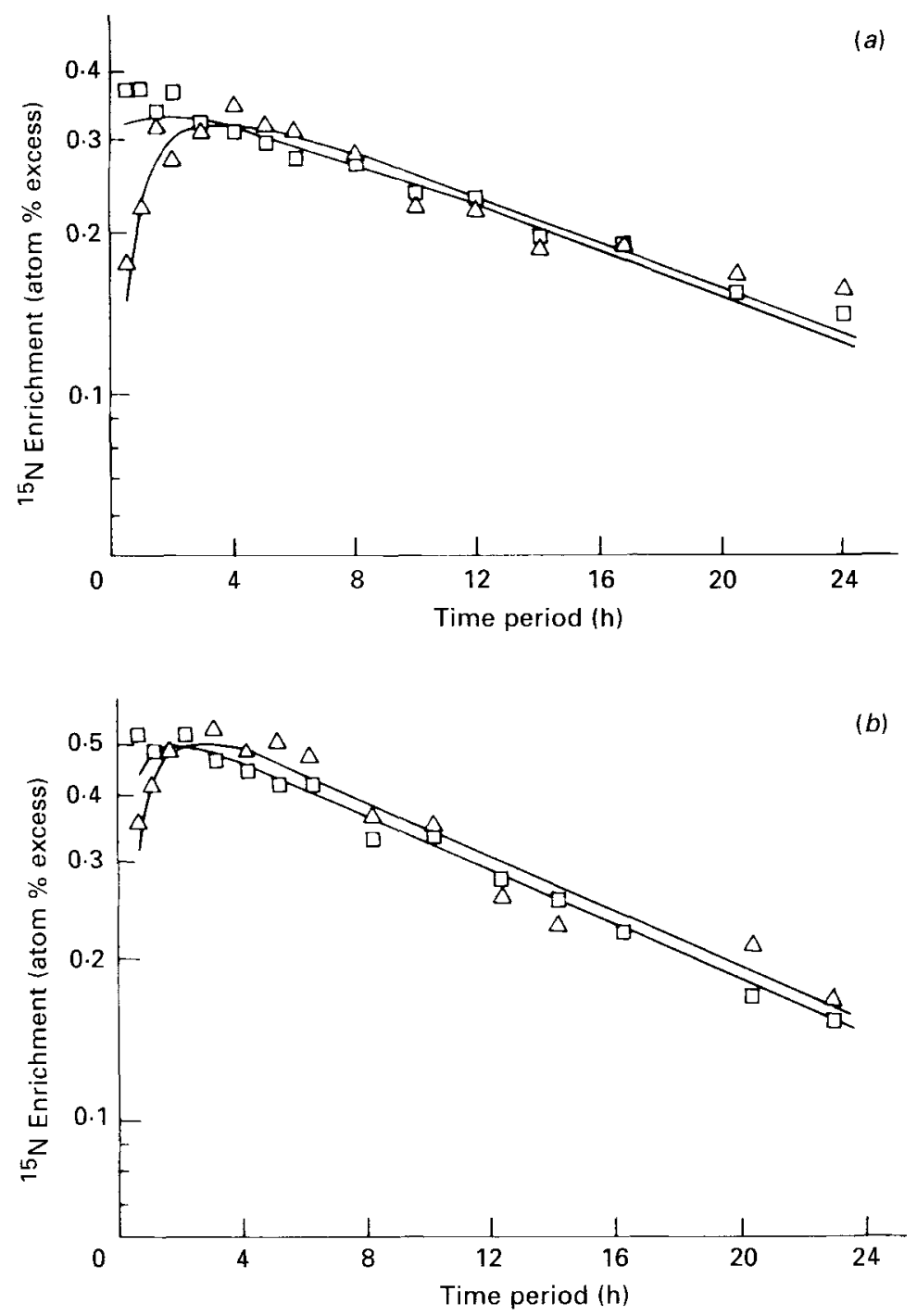

Fig. 5. Comparison of non-ammonia nitrogen and purine ${ }^{15} \mathrm{~N}$-enrichment curves of ram 2 given $(a)$ a diet containing fishmeal or $(b)$ a diet containing raw soya-bean meal. $(\triangle-\triangle)$, Rumen purines; $(\square-\square)$, rumen non$\mathrm{NH}_{3}-\mathrm{N}$.

synthetic NAN2 recycled to $\mathrm{NH}_{3}$ in the rumen was estimated to be $21.8 \%$ of the total synthesis of this pool. This value is close to the estimations of microbial $\mathrm{N}$ recycling of $20 \cdot 4$ and $24.3 \%$ that were reported by Nolan \& Leng (1972) and Mazanov \& Nolan (1976) respectively. The estimated recycling rates for the three rations in Expt 2 (Table 4) were $61.5,40.2$ and $55.3 \%$ for diets SBM, FM and RSBM respectively. Harmeyer \& Guldenhaupt (1980) found in studies in vitro that the total bacterial $N$ synthesis was at least twice the net bacterial $N$ synthesis. Leng \& Nolan (1984) later estimated that microbial recycling could exceed $50 \%$ and calculations of data presented by them show that $57 \cdot 3 \%$ of microbial $\mathrm{N}$ synthesis was recycled to $\mathrm{NH}_{3}$ in sheep given a semi-synthetic ration.

Considerable differences were found in SNAN2 recycling rate and other variables between Expt 1 and the diet SBM treatment in Expt 2. The absence of tapioca and the 
smaller portion of straw in the first experiment, leading to differences in physical form and in fibre content between the two diets, might permit quicker escape of both feed particles and microbial matter from the rumen, and could explain the lower degradability of both feed and microbial NAN.

Rumen NAN output was higher and $\mathrm{NH}_{3}$ net loss to the blood lower on diet FM than on the other two diets. As calculated by definition 2, all protein sources degraded to a similar extent of over $0.9(0.945,0.929$ and 0.906 for diets SBM, FM and RSBM respectively). These high degradation values leave only $6-10 \%$ of the dietary NAN escaping metabolism in the rumen. Czerkawski \& Breckenridge (1985) reported degradability values of 0.95 and 1.03 for diets FM and SBM respectively, when incubated for $48 \mathrm{~h}$ in a rumen-simulation apparatus. In recent studies in our laboratory (Aharoni \& Tagari, unpublished results) using milking goats and a milking cow at high feeding levels, a higher proportion of FNAN escaped metabolism in the rumen when the diets were supplemented by either SBM or FM, and it is suggested that this variable is affected more by the rate of feed passage than by the particular protein supplement used.

The proportion that was degraded directly to $\mathrm{NH}_{3}$ (definition 1) was smallest on diet FM and largest on diet RSBM $(0.229,0.115$ and 0.366 for diets SBM, FM and RSBM respectively). When adding the proportion of feed $\mathrm{N}$ that was degraded eventually to $\mathrm{NH}_{3}$ via the SNAN2 pool to the primary degradation (i.e. definition 3), dietary FM degraded to a lesser extent than the soya-bean diets. Calculated values of this degradation were 0.669 , 0.442 and 0.664 for diets SBM, FM and RSBM respectively. These values did not differ significantly, but there was a significant difference between diet FM and the soya-bean diets in the output of synthesized NAN $(R(0,4)+R(0,2)$ in Table 4$)$. Of the rumen NAN output, the proportion that was synthesized from $\mathrm{NH}_{3}$ was largest on diet RSBM $(0 \cdot 364,0.403$ and 0.491 for diets SBM, FM and RSBM respectively, $P<0.05$ ). However, the amounts of NAN synthesized de novo were calculated to be $2 \cdot 79,5.79$ and $4.36 \mathrm{~g} / \mathrm{d}$ for diets SBM, FM and $\mathrm{RSBM}$ respectively.

The greater efficiency of diet FM was predominantly the result of the higher rate of urea recycling to the rumen. The amounts of urea produced did not differ between treatments, but a larger proportion of it was directed to the rumen and less was excreted on diet FM. These results are not in agreement with results reported by Dawson et al. (1988). They found that when a diet of ryegrass (Lollium perenne) silage for steers was supplemented with FM, $67 \%$ of the increase in rumen NAN output was due to an increased flow of undegraded FNAN. Cottrill et al. (1982) found that replacement of urea by FM in lowenergy diets given to young steers considerably increased the flow of amino acids from the rumen. However, the same replacement in a high-energy diet decreased the flow of amino acids, suggesting a very high degradability of the FM N in high-energy diets. In both cases, addition of FM enhanced the flow of blood urea to the rumen. In the present study, on a high-energy diet 82.5 and $91.5 \%$ of the urea produced in the body was directed to excretion on diet SBM and RSBM respectively, compared with $45.3 \%$ on diet FM $(P<0.1)$. More than half the urea produced in the body on diet FM was recycled to the rumen and accounted for most of the difference in NAN output between diet FM and the soya-bean diets.

The $\mathrm{NH}_{3}$ pool turnover rate was fastest on diet FM and slowest on diet RSBM. This rate was not inversely correlated with pool size, as would be expected. The high exchange rate between the $\mathrm{NH}_{3}$ and SNAN1 pools was the main contributor to the high turnover rate of both pools. The exchange rate tended to be lower $(P<0 \cdot 1)$ for diet RSBM as compared with the other two diets $(R(2,1)$ and $R(1,2)$ in Table 4$)$, suggesting that the binding rate of $\mathrm{NH}_{3}$ to compounds in the rumen may be responsive to the composition of the protein source of the diet. When $\mathrm{NH}_{3}$ and SNAN1 pools were regarded as one combined pool 
$\left(\mathrm{NH}_{3}+\right.$ SNAN1 pool, Table 4$)$, the turnover rate of this pool did not differ significantly between treatments.

In the present study, significant differences in major rumen $\mathrm{N}$ metabolism flow rates were defined between the three protein sources, and between two individual animals, suggesting the possibility of defining rumen $\mathrm{N}$ metabolism in a research model that does not require microbial fractionation of rumen or duodenal contents.

\section{REFERENCES}

Aharoni, Y. \& Tagari, H. (1991). Use of nitrogen-15 determinations of purine nitrogen fraction of digesta to define nitrogen metabolism traits in the rumen. Journal of Dairy Science 74 (8), 2540-2547.

Berman, M., Shahn, E. \& Weiss, M. F. (1962). The routine fitting of kinetic data to models: a mathematical formalism for digital computers. Biophysical Journal 2, 275-287.

Boston, R. C., Greif, P. C. \& Berman, M. (1982). CONSAM (Conversational version of SAAM modeling program). In Lipoprotein Kinetics and Modelling [M. Berman, S. M. Grundy and B. V. Howard, editors]. New York: Academic Press.

Brosh, A. (1985). Metabolic effects of infrequent drinking and low quality feed on Beduin goats. PhD Thesis, Tel Aviv University.

Bruckental, I., Oldham, J. D. \& Sutton, J. D. (1980). Glucose and urea kinetics in cows in early lactation. British Journal of Nutrition 44, 33-45.

Bunting, L. D., Boling, J. A. \& Mackown, C. T. (1989). Effect of dietary protein level of nitrogen metabolism in the growing bovine. I. Nitrogen recycling and intestinal protein supply in calves. Journal of Animal Science 67, $810-819$.

Chaney, A. L. \& Marbach, E. P. (1962). Modified reagents for determination of urea and ammonia. Clinical Chemistry 8, 130-132.

Conway, E. J. (1957). Microdiffusion Analysis and Volumetric Error. London: Crosby Lockwood \& Son Ltd.

Cottrill, B. R., Beever, D. E., Austin, A. R. \& Osbourn, D. F. (1982). The effect of protein- and non-proteinnitrogen supplements to maize silage on total amino acid supply in young cattle. British Journal of Nutrition $\mathbf{4 8}$, $527-541$.

Czerkawski, J.W. \& Breckenridge, G. (1985). Metabolism of protein supplements studied by the rumen simulation technique (Rusitech). Archiv für Tierernahrung 35, 261-277.

Dawson, J. M., Bruce, C. I., Buttery, P. J., Gill, M. \& Beever, D. E. (1988). Protein metabolism in the rumen of silage-fed steers: effect of fishmeal supplementation. British Journal of Nutrition 60, 339-353.

Feigenbaum, S. \& Hadas, A. (1974). Method of sample preparation for ${ }^{15} \mathrm{~N}$ determination in soil extracts by emission spectrometry. Soil Science 117, 168-170.

Goering, H. K. \& Van Soest, P. J. (1975). Forage Fiber Analysis. Agricultural Handbook no. 379, Agriculture Research Survey. Washington, DC: US Department of Agriculture.

Harmeyer, J. \& Guldenhaupt, H. (1980). Measurements of protein turnover in batch cultures of rumen microbes using isotopic markers. In Protein Metabolism and Nutrition, pp. 49-55 [H. J. Oflage and K. Rohr, editors]. Proceedings of the 3rd EAAP Symposium. European Association for Animal Production, Publication no. 22. Braunschwerg, Germany: Information Center of Bundesforschungfanspalt.

Leng, R. A. \& Nolan, J. V. (1984). Symposium: Protein nutrition of lactating dairy cows. Journal of Dairy Science 67, 1072-1089.

Mazanov, A. \& Nolan, J. V. (1976). Simulation of the dynamics of nitrogen metabolism in sheep. British Journal of Nutrition 35, 149-174.

Nolan, J. V. \& Leng, R. A. (1972). Dynamic aspects of ammonia and urea metabolism in sheep. Britisi. Journal of Nutrition 27, 177-194.

Nolan, J. V., Norton, B. W. \& Leng, R. A. (1976). Further studies of the dynamics of nitrogen metabolism in sheep. British Journal of Nutrition 35, 127--147.

Salter, D. N., Denashvar, K. \& Smith, R. H. (1979). The origin of nitrogen incorporated into compounds in the rumen bacteria of steers given protein- and urea-containing diets. British Joumal of Nutrition 41, 197-209.

Smith, R. H. (1975). Nitrogen metabolism in the rumen and the composition and nutritive value of nitrogen compounds entering the duodenum. In Digestion and Metabolism in the Ruminant, pp. 399-415 [I. W. McDonald and A. C. I. Warner, editors]. Armidale, NSW: University of New England.

Titgemeyer, E. C., Merchen, N. R. \& Berger, L. L. (1989). Evaluation of soybean meal, corn gluten meal, blood meal and fish meal as sources of nitrogen and amino acids disappearing from the small intestines of steers. Journal of Animal Science 67, 262-275.

Zinn, R. A. \& Owens, F. N. (1982). Rapid procedure for quantifying nucleic acids content of digesta. In Protein Requirements for Canle: Symposium, pp. 26-30 [F. N. Owens, editor]. Stillwater, OK: Oklahoma State University. 